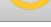

\title{
Biomechanical Analysis of Mawashi-Geri Technique in Karate: Review Article
}

\author{
Salar Hariri ${ }^{1}$ and Heydar Sadeghi ${ }^{2,{ }^{*}}$ \\ ${ }^{1}$ Sports Biomechanics, Sport Sciences Faculty, Tehran Central Branch, Islamic Azad University, Tehran, Iran \\ ${ }^{2}$ Sports Biomechanics, Faculty of Physical Education and Sport Sciences, University of Kharazmi, Tehran, Iran \\ "Corresponding author: Professor in Sports Biomechanics, Faculty of Physical Education and Sport Sciences, University of Kharazmi, Tehran, Iran. E-mail: sadeghih@yahoo.com
}

Received 2018 September 16; Accepted 2018 October 07.

\begin{abstract}
Mawashi-Geri Jodan technique (circular kicking to the opponent's head), is one of the most commonly used techniquesin the Karate, especially in the combat style. Although the speed of the implementation of the technique plays an important role in gaining points, there is no specific pattern for optimal performance of the technique. In this research, it was aimed at reviewing the results of the previous research that has been conducted on the effective issues relating to the success of this technique performance. The related articles were searched in ScienceDirect, PubMed, Google Scholar by considering the words like Karate, biomechanics, kinetic and kinetic analysis, EMG of Mawashi-Geri and EMG of kick. In the years ranging from 2000 to 2018, the findings of the research showed that the quadriceps muscles, especially rectus femoris muscle, played a major role in the efficacy of technique performance. Keeping the knee upward while rotating the body, the technique will be performed faster due to closer distance toward the opponent. Therefore, Karate player can obtain the required score more easily and quickly. It seems that the use of this pattern will be effective in performing the technique of Mawashi-Geri in Karate.
\end{abstract}

Keywords: Mawashi-Geri, Kinetics, Kinematic, Performance

\section{Context}

Karate as martial arts means a method of fighting and defending with an empty hand (without weapons) which involves rapid kicks (1). This sport is based on the techniques that involve punching, kicking, kneeling and elbows strikes (2). In addition, it is also consisted of skills and physical arts that is an active and dynamic (3) that involves multiple muscles. The activity of these muscles is associated with flexion, extension and rotation of various joints $(4,5)$. Foot techniques in Karate include MaeGeri, Mawashi-Geri, Ora Mawashi-Geriand Yoko-Geri. Jordan Mawashi-Geritechnique is the most common used technique in Karate (6) and is used more than any other onesin the Kumite (combat) races (7). In the Mawashi-Geri technique, the initial stage is the most important stage in the performance which needs high concentration $(8,9)$. Having considered the technique in geometric trajectory, the center of gravity is examined at two functional levels (abdominal area and face area) (10). It has been shown that total body balance, pelvic flexibility and controlling the body in Mawashi-Geri technique, plays a key role in the effectiveness of the technique in Kumite (combat). It is recommended that the foot rotation can be performed after the implementation of the technique in order to prevent the opponent from attacking with coordination and control (11). Due to the fact that proper use of muscles plays an important role in the performance of Mawashi-Geri technique in Karate (4), the stabilizing muscles are of importance during knee extension, especially the medial muscle of the quadriceps (rectus femoris muscle) $(5,12)$. Studies by Lotfian et al. suggested that EMG activity was significantly higher in the tensor fasciae latae, sartorius and hamstring muscles in Mawashi-Geri technique (13). In Karate, speed is considered as a key factor in performance success $(7,14)$. The ability to do the rapid maneuvers and changing the directions while moving in the ground is of utmost importance $(15,16)$. To achieve maximum force in performing the techniques in Karate, regarding the timing in the techniques performance is influential $(17,18)$. It was shown in a study that increasing the knee speed and minimizing the time elapsed from the ground is effective in improving Mawashi-Geri technique (2). Estevan et al. also examined the speed of joints (pelvis, knees, ankles) and concluded that pelvic speed is faster than the knee and ankle joints (19). Generally, the need for increasing the knowledge about the optimal patterns for Mawashi-Geri tech- 
nique is felt, therefore, the purpose of this study was to review the biomechanical analysis of Mawashi-Geri technique in Karate.

\section{Data Collection}

A comprehensive literature search in Google Scholar, ScienceDirect, and PubMed were conducted to consider all relevant articles that investigated the analysis of Karate techniques. All papers were obtained between 2000 and 2018 with focusing on the words like Karate biomechanics, kinetic meta-analysis, EMG of Mawashi-Geri, EMG of kick and kinetic. A total of 12 articles were obtained based on inclusive criteria including biomechanical analysis of Karate techniques. Other descriptive, qualitative and overview articles were used to support the findings.

\section{Results}

Based on inclusion criteria (related articles), 12 articles were studied. In the field of biomechanics, the MawashiGeri technique are considerd in three sections of kinetic, kinematics analysis and electrical activity of the muscles.

\subsection{Kinetic Analysis of Mawashi-Gery Technique}

The research background for the kinetic analysis of Mawashi-Geri technique is presented in Table 1.

\subsection{Kinematics Analysis of Mawashi-Gery Technique}

The research background for analyzing the kinematics and Mawashi-Geri technique is presented in Tables 2 and 3.

3.3. Electric Activity of the Muscles in the Mawashi-Gery Technique

The background of the research on the electrical activity of the muscles in the Mawashi-Geri technique is presented in Table 4.

\section{Discussion}

\subsection{Kinetic Analysis of Mawashi-Gery Technique}

Figure 1 shows the center of gravity in two techniques of Mawashi-Geri and Mae-Geri skill during the various stages of performance. This suggests that there is an acceleration stage for performing the Mawashi-Geri technique, which is due to the movement of the body downward and then forward, and moves the action force to the muscles in the opposite direction. This causes the "soft landing" movement, which identifies the initial phase of motion, which is exactly the opposite of what happens to the initial phase. The reason for this is that the Mae-Geri technique does not require such preparation for the lower limb (20).

The researcher believes that the first phase is one of the most important phases in the implementation of both techniques. This phase is also the starting point for both groups of "Mawashi-Geri and Mae-Geri" techniques, and has been considered as a principle for the technique. So any success in performance of this stage leads to optimal pattern of the final technique. A study done on the main stage of the implementation of the Mawashi-Geri technique shows that sequential movements of a series of motions, such as the initial phase of motion, create a kind of deception and confusion for the opponent, which may create a vacuum or a stomp in the opponent's defensive guard (20).

The key parameters for success at this stage are the high level of attack execution and prediction of success, based on the opponent's reaction after hit. Also, the inclination to the base of the center of mass of the curve at the end of the motion is introduced as the cause of a kinetic change in the lower extremity for the implementation of the Jodan's Mawashi-Geri technique (head strikes) (20, 25, 26).

\subsection{Kinematic Technique of Mawashi-Gery Technique}

Figures 2 - 5 suggest the kinematics of the MawashiGeri technique; total time of the performance phases of the technique (preparation-technique performance-end of technique) which last for 1.20 seconds.

\subsubsection{Pelvis Joint of the Kicking Leg}

based on the Figure 2, the horizontal displacement (x) was between $1.80 \mathrm{~m}$ in the first frame and $2.63 \mathrm{~m}$ in the frame 17. The vertical displacement (y) was $0.82 \mathrm{~m}$ in frame 2 to $1.04 \mathrm{~m}$ in frame 13 . The speed was recorded from 0.17 $\mathrm{m} / \mathrm{s}$ in the first frame to $2.92 \mathrm{~m} / \mathrm{s}$ in frame 7 . The acceleration range was also calculated from $0.02 \mathrm{~m} / \mathrm{s}^{2}$ in frame 13 to $2.36 \mathrm{~m} / \mathrm{s}^{2}$ in frame 5 . Muscle strength was reported at a rate of $1.2 \mathrm{~N}$ in frame 13 to $1799 \mathrm{~N}$ in frame 5. The efficiency (power efficiency) was calculated from $0.09 \mathrm{~J} / \mathrm{s}$ in frame 13 to $329.46 \mathrm{~J} / \mathrm{s}$ in frame 6 . The highest values for power, efficiency, and speed were reported in frames 5, 6 and 7 respectively (23).

\subsubsection{Knee Joint of the Kicking Leg}

The horizontal displacement $(\mathrm{x})$ ranged from $1.69 \mathrm{~m}$ in the first frame to $3.16 \mathrm{~m}$ in the 16th frame. The vertical displacement (y) was 0.8 meters in frame 2 to 6.86 meters in frame 9. The speed was recorded at $0.12 \mathrm{~m} / \mathrm{s}$ in the first frame to $6.86 \mathrm{~m} / \mathrm{s}$ in frame 9. The acceleration range was calculated from $0.48 \mathrm{~m} / \mathrm{s}^{2}$ in the frame of 25 to $55.70 \mathrm{~m} / \mathrm{s}^{2}$ in 


\begin{tabular}{llll}
\hline Table 1. Kinetic Analysis of Mawashi-Geri Technique Research Background & Results \\
\hline Author & Subjects & Measurement Tool & $\begin{array}{l}\text { In the application of the Jodan head-to-head Mawashi-Geri } \\
\text { El-Daly (2010) } \\
\text { Karate from the Egyptian } \\
\text { national Karate team 1 person } \\
\text { movement of the body downward and then forward, whe } \\
\text { force of action moves to the muscles in the opposite direction } \\
(20) .\end{array}$ \\
\hline
\end{tabular}

\begin{tabular}{|c|c|c|c|}
\hline Author & Subjects & Measurement Tool & Results \\
\hline $\begin{array}{l}\text { Piemontez et } \\
\text { al. (2011) }\end{array}$ & $\begin{array}{l}\text { Karateka with a black belt and } \\
\text { a training experience of } 7.7 \pm \\
7 \text { years }(29.26 \pm 9.5 \text { years, } 8 \\
\text { persons })\end{array}$ & $\begin{array}{l}\text { To collect information from } 6 \text { cameras, each } \\
\text { Karateka scored three beats on a sandy bag. } \\
\text { Then the data was analyzed by the special } \\
\text { software 3D analysis and the operator and the } \\
\text { hit rate was obtained. }\end{array}$ & $\begin{array}{l}\text { The Karateka s performed a Mawashi-Geri technique that had } \\
\text { the following data for moving the ankle as follows: } 0.08 \pm \\
0.11 \text { seconds attack time, } 0.98 \pm 0.09 \text { seconds return leg after } \\
\text { attack, and speed of } 10 / 2 \pm 10.3 \mathrm{~m} / \mathrm{s} \text { for the attack. The attack } \\
\text { rate for the hip joint in this impact was } 76.4 \pm 1.74 \mathrm{~m} / \mathrm{s}(21) \text {. }\end{array}$ \\
\hline $\begin{array}{l}\text { Piemontez et } \\
\text { al. (2013) }\end{array}$ & $\begin{array}{l}\text { Shaboodo style Karate men } \\
\text { with black belt of Corrientes } \\
\text { Parana, Brazil ( } 20 \text { people) }\end{array}$ & $\begin{array}{l}\text { To collect information from six cameras, each } \\
\text { Karateka scored three beats on a sandy bag. } \\
\text { Then the data was analyzed by the special } \\
\text { software 3D analysis and the operator and the } \\
\text { impact velocity was obtained. }\end{array}$ & $\begin{array}{l}\text { In the implementation of the Mawashi-Geri technique of } \\
\text { pointing in the ankle movement: } 0.48 \text { seconds in the attack, } \\
0.18 \pm 0.07 \text { seconds for the foot to return after the attack, the } \\
\text { rate was } 43.9 \pm 1.01 \mathrm{~m} / \mathrm{s} \text { for the attack and } 04.07 \pm 0.07 / 2 \mathrm{~m} / \mathrm{s} \\
\text { on the back of the foot after the shot. Impact data were in the } \\
\text { knee joint with a speed of } 22.25 \pm 0.26 \mathrm{~m} / \mathrm{s} \text { for the attack, and } \\
2.70 \pm 0.14 \mathrm{~m} / \mathrm{s} \text { for foot restoration after the impact. In the } \\
\text { hip joint, the speed was } 32.34 \pm 0.37 \mathrm{~m} / \mathrm{s} \text { for the attack and } \\
1.32 \pm 0.13 \mathrm{~m} / \mathrm{s} \text { for the foot return after the injury }(21) \text {. }\end{array}$ \\
\hline $\begin{array}{l}\text { Quinzi et al. } \\
(\mathbf{2 0 1 3 )}\end{array}$ & $\begin{array}{l}\text { A man and elite Karateka, with } \\
15 \text { years of practice experience. } \\
\text { All athletes with black belt } \\
\text { were } 24.8 \pm 1,178 \pm 0.03 \mathrm{~cm} \\
\text { tall and } 73 \pm 4 \mathrm{~kg} \text { ( } 6 \text { persons) }\end{array}$ & $\begin{array}{l}\text { Data gathering angular velocity with a camera } \\
\text { on the SAT screen. Run-hit with } 3 \text { repetitions. } \\
\text { The impact was attacked on the target, on the } \\
\text { body (kekomi), and without impact on the } \\
\text { face (keage). The type of kick (with collision } \\
\text { and no collision) was determined according } \\
\text { to the rules of the World Karate Federation. }\end{array}$ & $\begin{array}{l}\text { The Elite Karateka s performed the Mawashi-Geri kekomi } \\
\text { technique at an angular velocity of } 1734 \pm 108^{\circ} \mathrm{C} \text { per second } \\
\text { (with collision) and a Mawashi-Geri keagetechnique that } \\
\text { performed the reaction at an angular velocity of } \pm 1633 \pm 102 \\
{ }^{\circ} \mathrm{C} \text { per second (without collision) for the knee joint. Extension } \\
\text { velocity of the hip joint in the attack phase was calculated for } \\
\text { the same athletes in the Mawashi-Geri kekomi technique, } \\
\text { which was } 628 \pm 60 \text { degrees per second (collisional) and } 375 \\
\pm 60 \text { degrees per second (without collision)(22). }\end{array}$ \\
\hline $\begin{array}{l}\text { Halawish } \\
(2011)\end{array}$ & $\begin{array}{l}\text { Elite Karateka s had a gold } \\
\text { medal in the Asian games of } \\
2011 \text { ( } 18 \text { years old, } 171,67 \mathrm{~kg} \text {, } \\
\text { long body length } 96 \mathrm{~cm}) .\end{array}$ & $\begin{array}{l}\text { Data collection was analyzed using the } \\
\text { Spector (two-dimensional) skill software and } \\
\text { the result rate of the impact was calculated. }\end{array}$ & $\begin{array}{l}\text { The implementation time of the Mawashi-Geri technique } \\
\text { performed by a Karateka was 120/0 seconds (23). }\end{array}$ \\
\hline $\begin{array}{l}\text { Gavagan and } \\
\text { Sayers (2017) }\end{array}$ & $\begin{array}{l}\text { kinematics performed by } \\
\text { highly skilled Muay Thai, } \\
\text { Karate and Taekwondo } \\
\text { practitioners ( } \mathrm{n}=8 \text { per group) }\end{array}$ & $\begin{array}{l}\text { Three-dimensional (3D) lower limb } \\
\text { kinematics were recorded using a nine } \\
\text { camera infra-red motion capture system ( } 500 \\
\text { Hz) during three maximal roundhouse kicks. } \\
\text { Impact forces were recorded using a strain } \\
\text { gauge (1000 Hz) attached to a kicking pad } \\
\text { positioned at the height of each participant's } \\
\text { mastoid process. }\end{array}$ & $\begin{array}{l}\text { Our findings show that several fundamental movement } \\
\text { patterns were common to the roundhouse kicking } \\
\text { techniques across the Muay Thai, Karate, and Taekwondo } \\
\text { disciplines. Effective roundhouse kicking performance was } \\
\text { characterized by rapid pelvic axial rotation, hip abduction, } \\
\text { hip flexion and knee extension velocities, combined with } \\
\text { rapid movements of the COM towards the target (16). }\end{array}$ \\
\hline
\end{tabular}

frame 6. Muscle strength was reported from $1.61 \mathrm{~N}$ in frame 25 to $186 \mathrm{~N}$ in frame 6 . The efficiency (power efficiency) was calculated from $0.73 \mathrm{~J} / \mathrm{s}$ in frame 2 to $989.74 \mathrm{~J} / \mathrm{s}$ in frame 10. The highest amount for power, efficiency and speed was reported in frames 9, 25 and 10 respectively (23).

\subsubsection{Metatarsus Joint of the Kicking Leg}

The horizontal displacement $(\mathrm{x})$ ranged from $1.58 \mathrm{~m}$ to frame 4 to $3.81 \mathrm{~m}$ in the frame 16 . The Vertical displacement $(y)$ ranged from $0.03 \mathrm{~m}$ to 26 frames to $1.25 \mathrm{~m}$ in frame 15. The speed was recorded from $0.08 \mathrm{~m} / \mathrm{s}$ in frame 5 to $9.84 \mathrm{~m} / \mathrm{s}$ in frame 11. The acceleration range was calculated from $0.19 \mathrm{~m} / \mathrm{s}^{2}$ in the frame of 30 to $96.86 \mathrm{~m} / \mathrm{s}^{2}$ in frame 14. The muscle strength was reported at a rate of $0.13 \mathrm{~N}$, in the frame 30 to $64.90 \mathrm{~N}$ in frame 14. Efficiency (power efficiency) was calculated from $0.05 \mathrm{~J} / \mathrm{s}$ in frame 30 to 358.17 $\mathrm{J} / \mathrm{s}$ in frame 14. The highest values for power, efficiency, and speed were reported in frames 11 and 14 respectively (23).

The researcher believes that frame 14 represents the maximum acceleration, power, and efficiency during the phase of the principle of motion. This is due to the close relationship between efficiency and power. The maximum speed in the phase of the principle of motion was recorded in frame 11 (23).This indicates that efficiency is a combination of speed and power. Karate practitioners state that strength, speed, and technique are recognizable from the path of the foot, and they are among the essential elements of the onset of skill $(17,19,21)$. Karate practitioners 
Table 3. History of Kinematic Analysis of Mawashi-Geri Technique

\begin{tabular}{lll} 
Author & Subjects & Measurement Tool \\
\hline $\begin{array}{l}\text { Emmermacher } \\
\text { et al. (2007) }\end{array}$ & $\begin{array}{l}\text { Skilled male Karateka at foot } \\
\text { stroke. 1 person orange belt } \\
\text { and 2 black belt. }\end{array}$ & $\begin{array}{l}\text { The data were recorded by the 8mx40 WiMax } \\
\text { system and then analyzed by the researcher } \\
\text { using the computer and analytical software } \\
\text { (two dimensional) and the impact velocity } \\
\text { was calculated. }\end{array}$
\end{tabular}

Results

The linear velocity of the shock was as follows: $2.29 \pm 0.27$ $\mathrm{m} / \mathrm{s}, 22.26 \pm 0.08$ and $2.54 \pm 0.29$ for the kizami

Mawashi-Geri technique, $0.05 \pm 0.05 \mathrm{~m}$ at $3.03 \pm 0.48 \mathrm{~m} / \mathrm{s}$ and Kekomi Mawashi-Geri $3.50 \pm 0.33$ for the Mawashi-Geri kekomi sampling technique, $0.36 \pm 0.17 \mathrm{~m} / \mathrm{s}, 0.38 \pm 0.11 \mathrm{~m}$ for the $S$ and $2.55 \pm 0.25 \mathrm{~m} / \mathrm{s}$ for the kishami sampling technique, which was $0.05 \pm 0.21 \mathrm{~m} / \mathrm{s}, 34.3 \pm 0.39 \mathrm{~m} / \mathrm{s}$ and $3.49 \pm 0.41$ $\mathrm{m} / \mathrm{s}$ for the Mawashi-Geri keage technique, which was the time when Mawashi-Gerikizami technique was used, which was also $0.68 \pm 0.60(9)$

$\begin{array}{ll}\begin{array}{l}\text { Hariri et al. } \\ \text { (2017) }\end{array} & \begin{array}{l}\text { Ten professional Karateka s } \\ \text { and } 10 \text { semi-professional } \\ \text { Karateka s were selected } \\ \text { purposefully and voluntarily. }\end{array}\end{array}$

Data gathering was performed using Skill Spector software and the total acceleration of the foot during run using a single axis accelerometer ADXL193 with a weight of $250 \mathrm{~g}$.
In their research, they concluded that there was a significant difference in the velocity of joint joints (pelvis, knee, knee joint), joint velocity (hip, knee, knee joint), total foot acceleration during joint and joint angles The knee is at the peak of speed between the two professional and semi-professional groups. Probably the reason for this difference is that the professional Karateurs start the Mawashi-Geri technique by lifting the knee while simultaneously turning the body and pushing the opponent with the bone on the bone. Semi-carat Karate at the start of the Mawashi-Geri technique, the foot moves rotational with the rotation of the body, then the knee is opened and bumped into the opponent's bone. Due to the lack of distance and skill in implementing the technique, professional-level professional Karatekas have more technique than semi-professional Karatekas (7).

Implementing the Mawashi-Geri technique with knee initiation due to lack of distance and uniformity of the first phase of the technique makes it difficult for the opponent to recognize the impact and the chance to hit and score points up takes. Therefore, it is recommended that coaches use this template to speed up the implementation of the technique and score points (6).

\section{Hariri et al.}

(2018)
Sixteen Karate from the Iranian National Army Corps were selected purposefully and voluntarily.
The data was collected using two Hero3 digital cameras (240 frames per second). Finally, in order to calculate the kinetics of the Mawashi-Geri technique, the kinematic parameters were introduced into the dynamical model, which was used by a mechanical simulator software, one of the software tools of the MATLAB.

Table 4. The Background of Electrical Activity Research of Mawashi-Geri Technology

\begin{tabular}{|c|c|c|c|}
\hline Author & Subjects & Measurement Tool & Results \\
\hline El-Daly (2010) & $\begin{array}{l}\text { One Karateka from the } \\
\text { Egyptian National Karate Team }\end{array}$ & $\begin{array}{l}\text { Electric activity of } 8 \text { muscles measured with } \\
\text { EMG device. }\end{array}$ & $\begin{array}{l}\text { In their study of the electrical activity of the muscles in the } \\
\text { Mawashi-Geri technique, it was concluded that the stabilizing } \\
\text { muscles, especially the quadriceps muscles (rectus femoris), } \\
\text { play an important role in the efficiency of the technique (20). }\end{array}$ \\
\hline $\begin{array}{l}\text { Hu et al. } \\
(2015)\end{array}$ & $\begin{array}{l}\text { Fourteen Karatekas in the } \\
\text { national group with an } \\
\text { average age of } 23.62 \text { years and } \\
14 \text { Karate in the control group } \\
\text { with an average of } 22.83\end{array}$ & $\begin{array}{l}\text { Electric activity of the muscles of the } \\
\text { gastrocnemius R, gastrocnemius L, tibialis } \\
\text { anterior R, tibialis anterior L, biceps femoris R, } \\
\text { biceps femoris L, rectus femoris R, rectus } \\
\text { femoris L, gluteus maximus R, gluteus } \\
\text { maximus L, gluteus medius R, gluteus medius } \\
\text { L, tensor fasciae latae R, tensor fasciae latae L, } \\
\text { rectus abdominis R, erector spinae R device16 } \\
\text { channels were measured. }\end{array}$ & $\begin{array}{l}\text { In their research, they investigated the order of invoking the } \\
\text { muscles involved in the microscopic technique and } \\
\text { concluded that in both groups (national and control), the } \\
\text { right biceps femoris muscle was torn to the right, followed by } \\
\text { the gastrocnemius muscle. Then, after the technique (firing } \\
\text { or blasting techniques or opening the technique), the } \\
\text { national team has a better reaction time than the control } \\
\text { group. In other words, in the national group, the order of the } \\
\text { inversion of the left leg muscles with the tibialis anterior } \\
\text { muscle, followed by the biceps muscle, is activated in the final } \\
\text { stage of the gastrocnemius muscle. But in the control group, } \\
\text { the right abdominal muscle is activated sooner than other } \\
\text { muscles. This subtle difference significantly reduces the } \\
\text { reaction time (24). }\end{array}$ \\
\hline
\end{tabular}

need to be careful that their exercises can improve muscle strength. This issue was also expressed by several other researchers $(9,15,16,21,23)$.

\subsubsection{Kicking LegJoints}

It is noteworthy that formative characteristics of body position during phases of motor performance change due to the change of the geometric path in primary movement. 


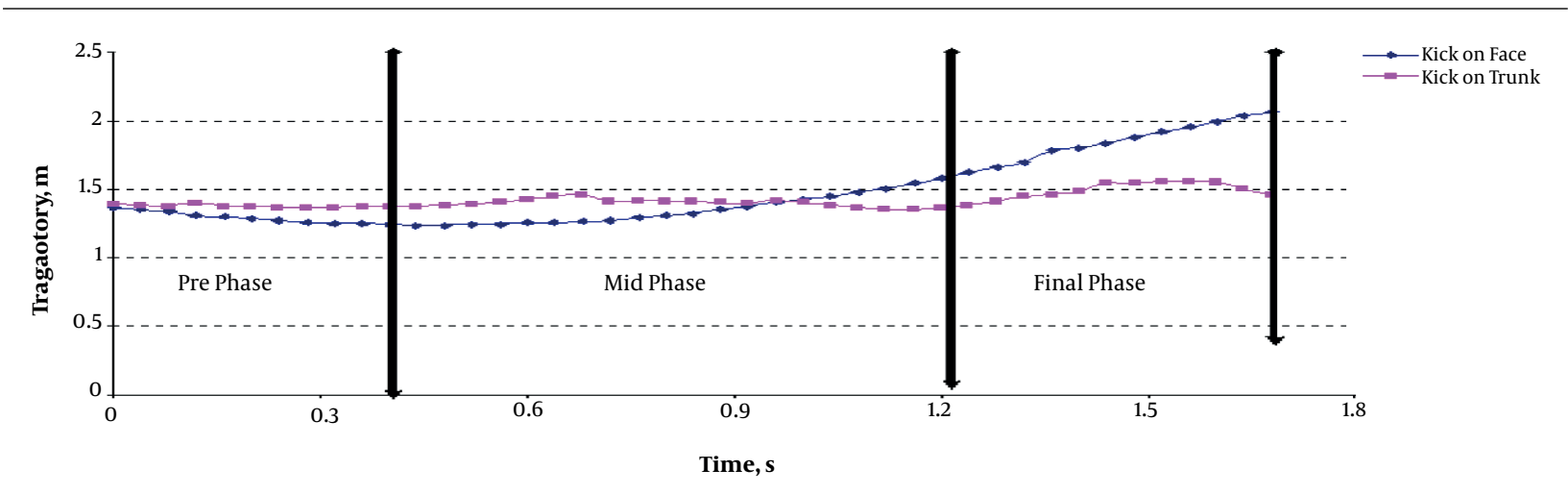

Figure 1. The geometric path of its center-holders Mawashi-Geri and Mae-geri techniques

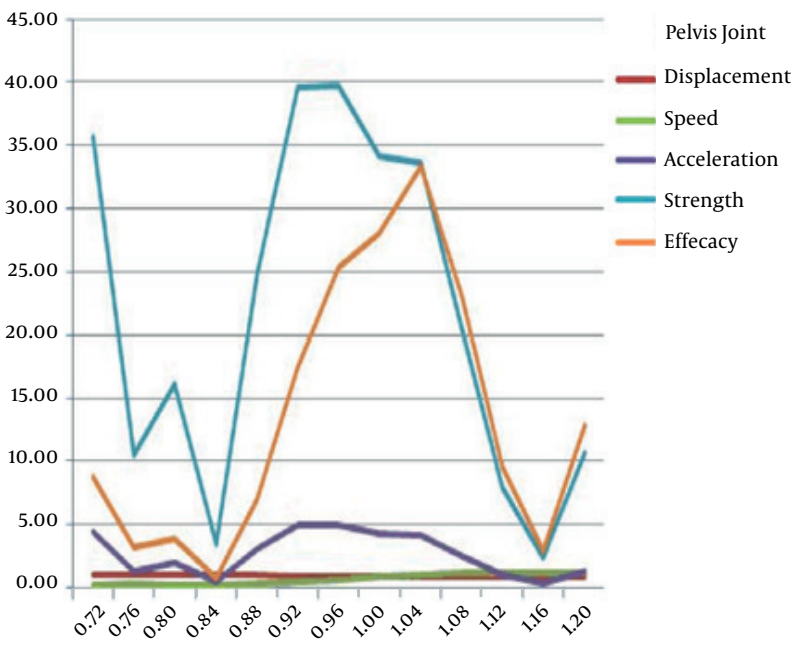

Figure 2. Pelvic geometric path at the beginning and end of the Mawashi-Geri technique

This indicates that working joints angles during technical performance vary and coaches should take special care for them, especially those angle in which the maximal moment is produce produced for improving the technique efficiency (23).

\subsubsection{Metatarsal Angle}

The Figure 5 suggests that in the preparation phase, the metatarsal angle was ranged between $118.19^{\circ}$ in $0.04 \mathrm{~s}$ for frame 1 to $128.20^{\circ}$ in $0.28 \mathrm{~s}$ for frame 7 respectively. In the phase of the major motion, this value was recorded at $138.88^{\circ}$ in 0.36 s for frame 9 , and 17 frames per second to $177.68^{\circ}$ in $0.56 \mathrm{~s}$ for frame 14 , respectively. For the end-ofmotion phase, the range of this angle was from $121.32^{\circ}$ in $0.84 \mathrm{~s}$ for frame 21 and $152.71^{\circ}$ in $0.72 \mathrm{~s}$ for frame 18 (23).

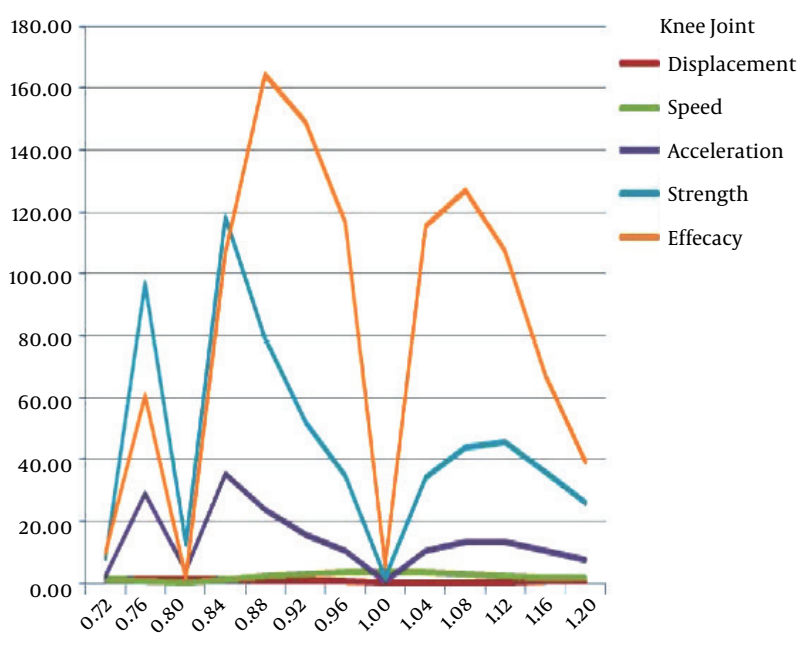

Figure 3. The knee joint geometry at the start and end of Mawashi-Geri technique

\subsubsection{Knee Joint Angle}

As show in Figure 5, in the preparation phase, the angle of the knee was between $108.57^{\circ}$ in $0.32 \mathrm{~s}$ for frame 8 to $173.24^{\circ}$ in $0.16 \mathrm{~s}$ for frame 4 , respectively. In the phase of the principle of motion, this value was recorded at $84.69^{\circ}$ in $0.36 \mathrm{~s}$ for frame 9 and $177.73^{\circ}$ in $0.56 \mathrm{~s}$ for frame 14 , respectively. For the end-of-movement phase, the range of this angle was $78.42^{\circ}$ in $0.76 \mathrm{~s}$ for frame 24 to $177.30^{\circ}$ in $0.72 \mathrm{~s}$ for frame 18 (23).

\subsubsection{Pelvic Joint Angle}

As show in Figure 5, in the preparation phase, the pelvic angle was between the $143.56^{\circ}$ in $0.04 \mathrm{~s}$ for frame 1 to $176.74^{\circ}$ in $0.32 \mathrm{~s}$ for frame 8 . In the phase of the major movement, this rate was recorded at $126.24^{\circ}$ in $0.68 \mathrm{~s}$ for frame 17 to $171.76^{\circ}$ in $0.36 \mathrm{~s}$ for frame 9 . For the end-of-movement phase, the range of this angle was $131.81^{\circ}$ in $0.72 \mathrm{~s}$ for frame 


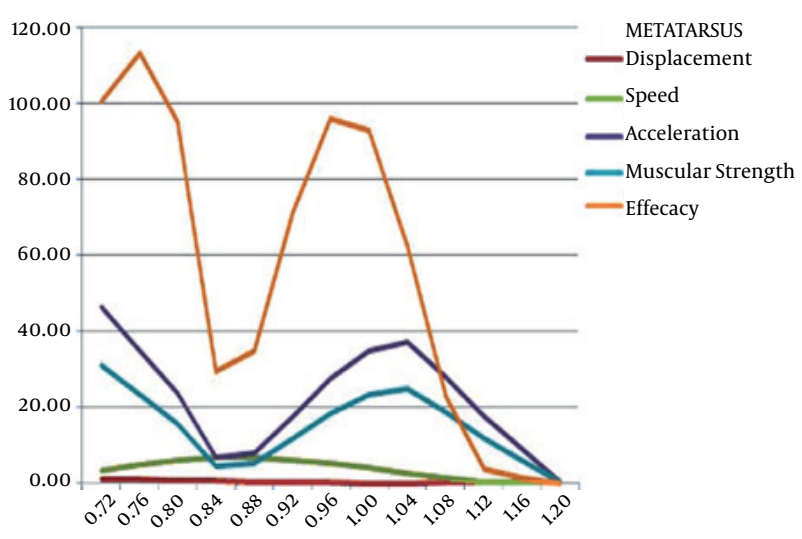

Figure 4. Metatarsal geometric path at the beginning and end of the Mawashi-Geri technique

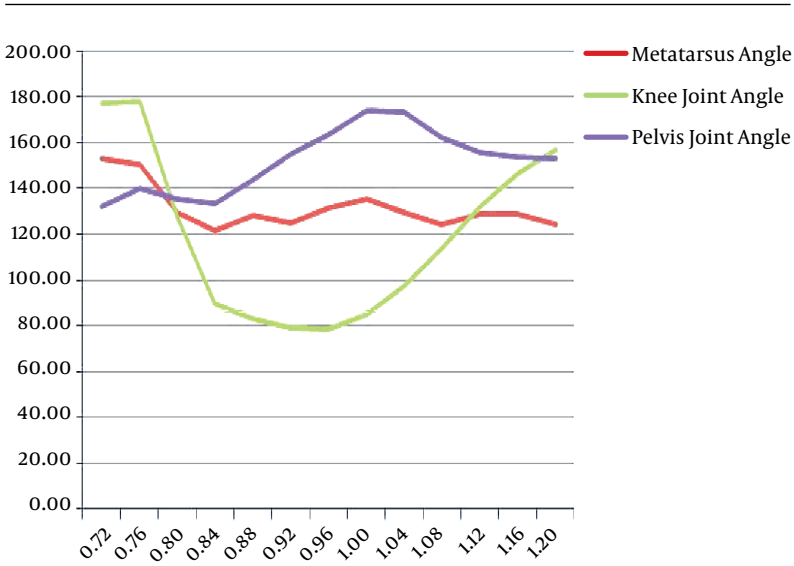

Figure 5. Angle of joints (metatarsal, knee, and pelvic) at the start and end of the Mawashi-Geri technique

18 to $174.17^{\circ}$ in $1.00 \mathrm{~s}$ for frame 25 (23).

Therefore, it is concluded that during the initial phase of motion, there is a direct relationship between the change in the angle of the joints of the metatarsal and knee. This causes smooth motion and increased velocity, as well as an inverse relationship between the two values and the angina values of the pelvis (23).This causes the kicker to reach the height necessary for the execution $(8,17)$. The researcher has concluded that the speed of the run increases with the increase of the hip joint angle. The maximum rate of metatarsal marker in the principle of motion was 9.84 $\mathrm{m} / \mathrm{s}$, which occurred in frame 11, while in frame 9 and sec 0.36 , the hip angle was 177.76 . The researcher believes that this angle describes the technical performance of the skill (23).

Given this kinematic analysis and angular momentum, improving muscle performance and opposing movement in each joint with the aim of balancing is a very important point $(21,23)$. It is very important that if the athlete's muscle quality improves, then exercises are chosen to strengthen both sides of the muscle and joint both sides of the body. Improving certain physical abilities in many sports activities is very important $(1,23,27)$. Muscular power is a very important motor parameter that results from the combination of muscular strength and the maximum speed of the implementation of a coordinated motor pattern $(16,23)$. In fact, this parameter is the most important element of skill performance in many sports (28). Power depends on muscular strength and speed, both of the most important requirements of the most sports fields, and especially for martial arts athletes, is the ability to control the opponent $(23,29)$.

The researcher believes that performing exercise performance should be the standard for determining the success of the training program. For speed sports, which in fact is the speed of performance, it is recommended to use the same exercises as the sports themselves $(5,23)$. Most of the training theories to strengthen and prepare the muscles, with certain methods that are similar to the actual exercise technique of the person $(17,29)$. Improving muscle performance due to the need for the simultaneous implementation of technical skill is a key factor for using the work of the nervous system muscle $(23,30)$. The best way to increase your strength is to sync your training periods with the actual time of the athlete. Also, it should be noted that dynamic training is better and more useful than static strength training $(20,23)$.

Emmermacher et al. also studied the Mawashi-Geri technique of the front leg and the back leg. The results of this study show the difference between the semicircular paths in the Mawashi-Geri technique. In the application of the maximization technique with the back leg at first, the path of motion is almost smooth, and at the end of the motion, the movements is semicircular. On the contrary (at the beginning of the path), when the Mawashi-Geri technique is performed by front leg, it is completely different in a form of semi-circular (9). Looking at the direction of motion in the performance of the technique by front leg, it can be said that the semicircular path is observed only in the end phases of the motion (18). In the initial phase of the motion in kicker leg, the path of motion is not semicircular. The end position of the body that first moves, is that the foot moves toward down and out. This position is necessary to follow the semicircular path. The cause of this pathway is that the opponent cannot detect the movement $(9,28)$.

Based on the results, it is necessary to increase the center of gravity of the body during Mawashi-Geri performance, in which long Karateka are more successful. In 
addition, The speed of the hit when contacting the opponent, has a great impact on the success of the technique. It should be noted that, the hip joint is more involved in the successful performance compared to knee joint (12). Therefore, the length of the thigh plays an important role in the speed of technique(1) and also the highest average of speed is produced in $82 \%$ of the length of the leg (31). This length can be considered as a desirable value for achieving maximum dynamic impact $(2,17,18)$.

\subsection{Electrical Activity of the Muscles in the Mawashi-Geri Tech- nique}

It was shown in a study that the Sequence of Muscle Recruitment in the national athletes and non-athletes were the same and two muscles (biceps femoris and right gastronomic muscles) initially activated. After these two muscles, the right tibialis anterior, the left tibialis anterior and the left biceps femoris were activated. In the national athletes, the left tibialis anterior was stimulated firstly, the left biceps femor was secondly activated and the right tibialis anterior was last in the three muscles. In the control group, two tibialis anteriors were almost at the same time, then followed by the left biceps femoris. The national athletes use the left tibialis anterior to speed up their kicking action. For the final three firing muscles in the national group, the left gastrocnemius was earlier activated than the right rectus abdominis, in the control group vice versa. Compared to the control group, the national team had a significantly shorter exercise time and started activating the muscles in them faster, which could be attributed to the fact that athletes in the national Karate. They can hit the target much faster than the control group. Starting faster activation of the lower limb muscles, along with a significant difference in the pattern of invoking other muscles $(17,24)$. It can be the main reason for this.

The sequence of muscle recruitment and total reaction time were investigated in both groups during performance of the technique. In both national and control groups, firstly, Biceps femoris muscle of right leg was picked up, followed by a gastrocnemius muscle recruiment, but the sequencing pattern of the next muscle was slightly different. The national team was willing to use a tibialis anterior right as the third muscle to be recruited, then the left Biceps femoris muscle was activated, and eventually the left gastrocnemius muscle and right rectus abdominis muscle tended to be activated. These differences in the pattern of muscle recruitment and the faster activation of the first few muscles may be effective in reducing reaction time in the national group $(17,24,32)$. The data of this research and its results can be useful in helping training the Karate athletes.

\section{Conclusion}

In Karate campaigns, the speed of techniques plays a significant role in the success of the Karateka. By analyzing the kinetic and the electrical activities of the techniques of the Mawashi-Geri, the best possible speed in performing the techniques should be achieved. The results indicate that starting motion from the proximal to distal part as the base pattern should be considered seriously by coaches. Also, in order to achieve maximum foot speed towards the target, it is necessary to increase the speed of the knee and reduce the time of lifting up the ground in the performance of the Mawashi-Geri technique. The activation of the hip muscles and the observation of the amount of activity of each involved muscle can be achieved by a better pattern of Mawashi-Geri techniques. In order to summarize the results, it was concluded that, if the MawashiGeri technique starts with kneeling up and simultaneously turning the body and then hit the opponent with the part on the bone of the foot. Due to lack of distance and being skillfull in performing technique, Karateka can quickly achieve the technique faster and gain more points. It seems that the use of this pattern will be effective in speeding up the implementation of the techniques.

\section{Footnotes}

Authors' Contribution: Salar Hariri reviewed the articles and wrote the manuscript. Heydar Sadeghi managed the review.

Conflict of Interests: The authors declare no conflict of interest.

Funding/Support: The authors declare no funding support.

\section{References}

1. Pappas E. Boxing, wrestling, and martial arts related injuries treated in emergency departments in the United States, 2002-2005. J Sports Sci Med. 2007;6(CSSI-2):58-61. [PubMed: 24198705]. [PubMed Central: PMC3809053].

2. Wasik J, Czarny W, Malolepszy E, Drozdek-Malolepsza T. Kinematics of Taekwondo front kick. Arch Budo Sci Martial Art Extreme Sports. 2015;11:23-8.

3. Camomilla V, Sbriccoli P, Quinzi F, Bergamini E, Mario A, Felici F, editors. Roundhouse kick with and without impact in Karateka of different technical level. ISBS-Conference Proceedings Archive. 2009.

4. Khanzadeh S, Sadeghi H, Choghagalani SK, Hoseiynpour S. Muscle stimulation timing while implementing Ura Mawashi Geri in Iranian elite women. J Hum Sport Exercise. 2015;10(Special Issue 2). doi: 10.14198/jhse.2015.10.Proc2.06.

5. Kim TW, Lee SC, Kil SK, Kang SC, Lim YT, Kim KT, et al. Kicking modality during erratic-dynamic and static condition effects the muscular co-activation of attacker. J Sports Sci. 2017;35(9):835-41. doi: 10.1080/02640414.2016.1192672. [PubMed: 27268278]. 
6. Hariri S, Sadeghi H, Ghiamirad A. Presenting a biomechanical model to examine the dynamic arameters of two implementations methods of Jodan Mawashi-Geri technique in elite male Karate players. 11th International Congress on Sport Sciences. 2018.

7. Hariri S, Sadeghi H, Kohan PS. Comparison of the selected kinematic variables Mawashi-Geri technique of professional and semiprofessional Karatekas aimed at presenting optimum pattern.10th International Congress on Sport Sciences. 2017.

8. Rinaldi M, Nasr Y, Atef G, Bini F, Varrecchia T, Conte C, et al. Biomechanical characterization of the Junzuki Karate punch: Indexes of performance. Eur J Sport Sci. 2018;18(6):796-805. doi: 10.1080/17461391.2018.1455899.

9. Emmermacher P, Witte K, Bystryzycki S, Potenberg J, editors. Different variations of the Karate technique Mawashi-Geri. ISBS-Conference Proceedings Archive. 2007.

10. VencesBrito AM, Rodrigues Ferreira MA, Cortes N, Fernandes O, Pezarat-Correia P. Kinematic and electromyographic analyses of a Karate punch. J Electromyogr Kinesiol. 2011;21(6):1023-9. doi: 10.1016/j.jelekin.2011.09.007. [PubMed: 22005009].

11. Alsamad T. The kinematics analysis of doubles kazami Mawashi-Geri for heavy weight players under the maximum load in Karate. World J Sports Sci. 2012;7(1):16-9.

12. Zago M, Codari M, Iaia FM, Sforza C. Multi-segmental movements as a function of experience in Karate. J Sports Sci. 2017;35(15):1515-22. doi: 10.1080/02640414.2016.1223332. [PubMed: 27560105].

13. Lotfian S, Cherati AS, Jamshidi A, Sanjari MA. Assessment of correlation between electrogoniometer measurements and sports-specific movement in Karate elites. Asian J Sports Med. 2014;5(2):115-22. [PubMed: 25834705]. [PubMed Central: PMC4374612].

14. Edwards DA, Buckmire R, Ortega-Gingrich J. A mathematical model of cinematic box-office dynamics with geographic effects. IMA J Manag Math. 2013;25(2):233-57. doi:10.1093/imaman/dpt006.

15. Mori S, Ohtani Y, Imanaka K. Reaction times and anticipatory skills of Karate athletes. Hum Mov Sci. 2002;21(2):213-30. [PubMed: 12167300].

16. Gavagan CJ, Sayers MGL. A biomechanical analysis of the roundhouse kicking technique of expert practitioners: A comparison between the martial arts disciplines of muay thai, Karate, and Taekwondo. PLoS One. 2017;12(8). e0182645. doi: 10.1371/journal.pone.0182645. [PubMed: 28841670]. [PubMed Central: PMC5571909].

17. Safar Cherati A, Lotfian S, Jamshidi A, Sanjari MA, Razi M. The effect of increasing volume of exercise on activation pattern of vastus medialis and lateralis and its correlation with anterior knee pain in Karate elites. Asian J Sports Med. 2016;7(3). e35289. doi: 10.5812/asjsm.35289. [PubMed: 27826403]. [PubMed Central: PMC5098113].

18. Holbling D, Preuschl E, Hassmann M, Baca A. Kinematic analysis of the double side kick in pointfighting, kickboxing. $J$ Sports Sci. 2017;35(4):317-24. doi: 10.1080/02640414.2016.1164333. [PubMed: 27018535].

19. Estevan I, Falco C, Silvernail JF, Jandacka D. Comparison of lower limb segments kinematics in a taekwondo kick. An approach to the proxi- mal to distal motion.J Hum Kinet. 2015;47:41-9. doi:10.1515/hukin-20150060. [PubMed: 26557189]. [PubMed Central: PMC4633266]

20. El-Daly AMS. Biokinematical analysis for "Mai-Mawashi Geri" based on two different levels of the competitors body in Karate. World J Sport Sci. 2010;3(3):161-7

21. Piemontez GR, Martins ACV, Melo SIL, Ferreira L, Reis NF. [Kinematics of the semicircular kick in Karate: comparison between the attack and return phases]. J Phys Edu / UEM. 2013;24(1). Portoguese. doi 10.4025/reveducfis.v24i1.18190.

22. Quinzi F, Camomilla V, Felici F, Di Mario A, Sbriccoli P. Differences in neuromuscular control between impact and no impact roundhouse kick in athletes of different skill levels. J Electromyogr $\mathrm{Ki}$ nesiol. 2013;23(1):140-50. doi: 10.1016/j.jelekin.2012.09.006. [PubMed: 23089236]

23. Halawish AMT. Kinematics of the mawashi shoudan kick as a parameter of designing a training program for Karate juniors. World J Sport Sci. 2011;5(4):237-44.

24. Hu C-C, Li J-D, Hsieh F-H, Lu T-W, editors. Muscle recruitment sequence and total reaction time during a Karate roundhouse kick. ISBSConference Proceedings Archive. 2016.

25. Wasik J. Kinematics and kinetics of Taekwondo side kick. J Hum Kinet 2011;30:13-20. doi: 10.2478/v10078-011-0068-z. [PubMed: 23486086]. [PubMed Central: PMC3588635].

26. Wasik J, da Silva Santos JF, Franchini E. Movement structure and kinetics of the traditional straight punch: Measurements in Taekwondo athletes. Ido Move Cult: J Martial Arts Anthropol. 2013;13(1):42-7. doi: 10.14589/ido.13.1.6.

27. Quinzi F, Bianchetti A, Felici F, Sbriccoli P. Higher torque and muscle fibre conduction velocity of the Biceps Brachii in Karate practitioners during isokinetic contractions. J Electromyogr Kinesiol. 2018;40:817. doi: 10.1016/j.jelekin.2018.04.005. [PubMed: 29698877].

28. Petri K, Lichtenstein M, Bandow N, Campe S, Wechselberger M Sprenger D, et al. Analysis of anticipation by 3D motion capturing - A new method presented in Karate Kumite. J Sports Sci. 2017;35(2):130-5. doi: 10.1080/02640414.2016.1158851. [PubMed: 26967837].

29. Gulledge JK, Dapena J. A comparison of the reverse and power punches in oriental martial arts. J Sports Sci. 2008;26(2):189-96. doi: 10.1080/02640410701429816. [PubMed: 17943591].

30. Zvonar M, Kolarova K, Zahradnicek V, Reguli Z, Vit M. Kinematic analysis in combative sports. Ido Move Cult: J Martial Arts Anthropol. 2012;12(1-4):115-22.

31. Pozo J, Bastien G, Dierick F. Execution time, kinetics, and kinematics of the Mae-Geri kick: Comparison of national and international standard Karate athletes. J Sports Sci. 2011;29(14):1553-61. doi: 10.1080/02640414.2011.605164. [PubMed: 21995835].

32. Raquel G, Namba EL, Bonotto D, Ribeiro Rosa EA, Trevilatto PC, Naval Machado MA, et al. The use of a custom-made mouthguard stabilizes the electromyographic activity of the masticatory muscles among Karate-Do athletes. J Bodyw Mov Ther. 2017;21(1):109-16. doi 10.1016/j.jbmt.2016.05.007. [PubMed: 28167165]. 